\title{
Educação escolar indígena e os reflexos de um imaginário social: uma leitura sob o viés da análise do discurso
}

\author{
Native school education and the imaginary social reflexes: a reading under the \\ discourse analysis
}

Nara Maria Fiel de Quevedo Sgarbi ${ }^{1}$

Centro Universitário da Grande Dourados

Alexandra Aparecida de Araújo Figueiredo ${ }^{2}$
Universidade Estadual do Oeste do Paraná

- RESUMO: O presente trabalho pretende realizar uma leitura acerca dos discursos que constituem o imaginário social em relação ao indígena na sociedade brasileira, mais especificamente, das aldeias do Município de Dourados/MS. Para a reflexão, traremos o enunciado- "As crianças da aldeia não nascem espertinhas como as da cidade", presente na narrativa de uma professora. O trecho narrativo é um recorte do trabalho desenvolvido por Figueiredo, (2013), nas escolas indígenas do referido município. Como base teórica para esse trabalho, nos pautamos nas concepções da Análise do Discurso (AD) de linha francesa, mais pontualmente em Pêcheux (1988) no que tange a questão de formação discursiva (FD) e formação imaginária (FI), por entendermos que os dizeres da atualidade estão atrelados a outros discursos constituídos ao longo da história. Nesse sentido, buscamos como pano de fundo, o texto - "Para além do pensamento abissal: das linhas globais a uma ecologia de saberes" do autor sociólogo, Boaventura de Sousa Santos, por entender que o mesmo possibilita uma visualização da existência de divisão radical da realidade em "deste lado da linha" e "do outro lado da linha" que relega o outro lado à inexistência, invisibilidade e exclusão. (SANTOS, 2010, p. 23).

- PALAVRAS-CHAVE: Análise do Discurso. Imagem. Indígena.

- ABSTRACT: This present work intends to carry out a reading about discourses that forms the social imaginary in relation to the natives in Brazilian society, specially from Dourados villages, MS. In the view of the circumstances, we should consider the assertion - "The native children that not were born as shrewd as those from the city", which is presented in a teacher's narrative. This text is a cutting from a work developed by Figueiredo, (2013), in native schools of this city. As theoretical basis for this essay, we listed the Discourse Analysis (DA) from French ideas, in particular by Pêcheux (1988) with regard to the discourse formation (DF) and imaginary formation (IF) since we understanding that the current sayings are attaching to other discourses established over the history. So, we search as a backdrop, the text - "Para além do pensamento abissal: das linhas globais a uma ecologia de saberes" from socialogical author, Boaventura de Sousa Santos, by perceiving that he makes possible a reality visualization from an extreme division from reality in "this side of line" and "the other side of line" which disdain the another side to the nonexistence, invisibility and omission. (SANTOS, 2010, p. 23).

- KEYWORDS: Discourse Analysis. Image. Native.

\section{Condições de Produção}

\footnotetext{
${ }^{1}$ Pós-Doutora pela UEMS. Docente do Centro Universitário da Grande Dourados - UNIGRAN. sgarbi@unigran.br

${ }^{2}$ Doutoranda pela UNIOESTE. Bolsista da CAPES.
} 
As condições de produção de um discurso possuem relação intrínseca com as Formações Discursivas que são impostas pelas Formações Ideológicas, assim não há discurso neutro ou fora de qualquer interpelação ideológica. Isso posto, o termo ideologia se apresenta para a $\mathrm{AD}$ francesa como algo inscrito em práticas discursivas, em sua realidade material. Diante disso vejamos as condições de produção discursiva desse estudo.

O município de Dourados, segunda maior cidade do Estado, localiza-se cerca de $230 \mathrm{~km}$ da capital e por sua configuração multicultural pode ser entendida, como uma região de contexto complexo. Diz-se dessa forma ,porque a população desse município é composta por pessoas advindas de várias regiões do Brasil e de outros países. A complexidade aumenta porque, além da questão de imigração, trata-se de uma região considerada de fronteira; está a $110 \mathrm{~km}$ de Ponta Porã e Pedro Juan Caballero (fronteira seca).

A população que aqui vivia e ainda vive se caracteriza por vários grupos étnicos. Todavia, em Dourados há predominância da etnia Guarani (kaiowá/ñhandeva) e Terena. Considerando essas questões entende-se que há a construção de um mosaico sociocultural étnico e linguístico que por suas diferenças, inevitavelmente ,muitas vezes, são palcos de conflitos.

Como peça integrante desse mosaico, nesse município temos uma população indígena estimada em 13.000 pessoas, segundo dados do último censo do IBGE (oficial). Porém, segundo MACHADO, 2012 ${ }^{3}$, responsável pelos registros de nascimentos no posto da Funai na própria aldeia Jaguapiru, o número chegaria, hoje, a 15.000 indígenas. O índice de natalidade anual estaria em torno de 450 crianças.

Esses indígenas são pertencentes à três etnias Guarani kaiowá/Ñhandeva e Terena que vivem nas aldeias, Jagaupiru, Bororo e Panambizinho, todas consideradas aldeias rurais. Porém, com o crescimento da cidade, a distância entre as aldeias e o centro urbano é de aproximadamente cinco $\mathrm{km}$ somente. Entretanto o que ainda caracteriza essas aldeias como rurais são: a falta de estruturas como: saneamento básico, pavimentação, iluminação e sinalizações. Há poucas casas consideradas tradicionais e a grande maioria é de alvenaria. A imagem a seguir apresenta a proximidade do centro urbano e as aldeias indígenas. O mapa a seguir evidencia a localização das aldeias.

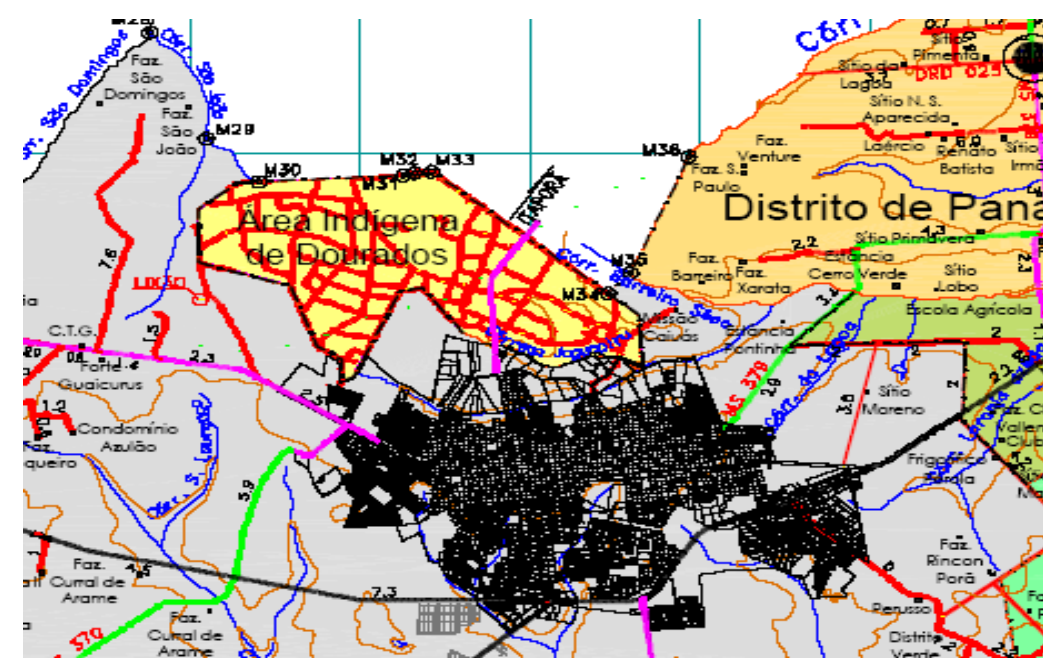

Fonte: Jesus \& Wenceslau (2006).

\footnotetext{
${ }^{3}$ Optamos por usar os dados fornecidos pelo Posto da Funai da aldeia Jaguapiru por entender que este retrata mais fielmente a realidade numérica da população indígena da aldeia Francisco Horta.
} 
Por esse mapa é possível perceber como a área indígena está entrecortada e limitada. O traçado rosa mostra a rodovia que entrecorta as aldeias Jaguapiru e Bororó. O traçado marrom mostra a perimetral construída para desafogar o trânsito pesado no centro de Dourados. Portanto, as aldeias estão ilhadas, sem condições de expansão. O mapa ainda permite visualizar a proximidade com o centro da cidade o que contribui para a instauração de vários problemas: realidade desse povo que as mídias local e nacional retratam, certamente, a partir de um ponto de vista tendencioso. Os conflitos não são apenas externos às aldeias, mas até mesmo entre os próprios moradores. É comum a veiculação nos noticiários, tanto escrito como televisivos, de indígenas atropelados em BR por estarem embriagados, assassinados por outros indígenas e casos de enforcamentos.

São sinais explícitos que já não é mais possível viver como viviam os antepassados de modo tradicional. Não há mais trabalhos para os homens nas aldeias, assim o que lhes restam são os empregos nas usinas de cana de açúcar ou em fazendas do município e região. A pesca, a caça, a busca pela matéria prima para seus artesanatos já não faz mais parte do cotidiano desse povo. Todavia, as plantas medicinais ainda compõem o conjunto de saberes indígenas, contudo, essas também se encontram escassas, quanto ao artesanato apesar da dificuldade em encontrar a matéria prima, também ainda é praticado com adaptações que utilizam materiais artificiais comprados em lojas especializadas.

De acordo com Brand (1997), os indígenas vivem em confinamento, porque as aldeias Jaguapiru e Bororó se localizam em um entroncamento que liga dois municípios - Dourados e Itaporã- como visto no mapa exposto. Sendo que, do primeiro município há uma distância de $5 \mathrm{~km}$ e do segundo $10 \mathrm{~km}$. Como se isso não bastasse, foi construída uma perimetral que margeia ao lado norte a aldeia Bororó. Nessa perimetral há trânsito intenso de caminhões que se deslocam no sentido Itaporã com destino à Ponta Porã. Portanto, as aldeias ficam impedidas de crescerem.

Vale destacar que entre os indígenas, culturalmente ,há o hábito de as famílias viverem de forma expandida. Dizendo de outra forma, quando filhos se casam, constroem suas casas nas proximidades de seus pais. Desta forma, compartilhando espaços. Essas práticas se fragilizam e, em virtude disto, em Mato Grosso do Sul a experiência tem mostrado a intensificação de acampamentos indígenas, como o caso do acampamento N handeru Laranjeira na rodovia que liga Dourados a Rio Brilhante e nas margens da perimetral em Dourados.

Faltam alternativas de sobrevivência dentro das aldeias e, em decorrência disto, percebe-se a presença de mulheres e crianças indígenas nos centros urbanos, buscando vender o pouco que conseguem produzir em seus quintais ,como mandioca, milho e galinha. A aldeia não consegue mais suprir as necessidades de seu povo. Nessa situação podemos inferir que para ser aceito esse povo é constantemente pressionado a mudar seu modo de agir, visto que é alvo de preconceitos, tanto cultural quanto linguístico.

É nesse cenário que se encontram escolas indígenas sob autarquia municipal. Os professores e gestores das escolas são, em sua maioria, indígenas. Para poucas áreas específicas como de Matemática e Ciências há docentes não indígenas. Os professores indígenas, em sua maioria, têm curso superior, alguns têm pós-graduação em nível de especialização e outros estão em formação e ,nesse caso, alguns deles na Licenciatura Intercultural Tako Arandu oferecida pela UFGD.

\section{Identidade}


Hoje nós indígenas e profissionais da área lutamos em prol de uma educação de qualidade, uma educação diferenciada bilingüe e intercultural. Pois somos diferentes, temos nossa cultura, nossa língua, nossa religião, nosso jeito de se diferente do Karai. (Professor indígena-Grifos nosso).

É a partir do/no olhar do outro que a identidade de um sujeito é constituída, do mesmo modo que são pelas representações reelaboradas discursivamente que, como jogo de espelhos, as imagens e as posições sociais são atribuídas. Logo, todo dizer está atrelado à posição de onde se fala, isso implica em sugerir que é desse lugar que o mesmo faz a imagem do outro, como explicitado no discurso do professor indígena com o qual iniciamos essa reflexão.

Para Pêcheux (1997, p. 85), “(...) a percepção é sempre atravessada pelo já ouvido e o já dito através dos quais se constitui a substância das formações imaginárias enunciadas". Isso é o que o filosofo francês institui como jogo de imagens.

Dessa forma, as diversas formações imaginárias são resultados delas mesmas. É nessa relação de imagens que estão inseridos os discursos dos e sobre os indígenas, logo são passíveis de deslizamentos/silenciamentos/deslocamentos de sentidos; isso porque o sujeito ao dizer, diz a partir de um lugar que é decorrente de relações imaginárias constituídas por formações ideológicas.

Nesse sentido, ainda sob as orientações de Pêcheux (1988, p. 162),ele indica que "(...)o funcionamento da ideologia como interpelação dos indivíduos em sujeitos, que se realiza por meio do complexo das formações ideológicas e especificamente pelo interdiscurso intricado nesse processo", ou seja, uma relação com outros já ditos, retomados pela memória discursiva, reelaborados conforme a conjuntura a qual se insere.

Assim, a situação de proximidade que o sujeito indígena possui com os centros urbanos, como no caso específico dessa pesquisa, possibilita que o mesmo transite por vários espaços em comum e tenha contato com diversas formações ideológicas, partilhe dos mesmos discursos e intradiscursos que interferem em sua realidade e, por conseguinte, em sua constituição identitária.

Cabe destacar que o fato de partilharem do mesmo contexto social não indica concordância absoluta sobre os discursos vinculados, até mesmo porque é uma situação muito díspare, ou seja, as condições sociais que os indígenas vivem fomentam uma imagem muito negativa a partir do olhar do não índio, contribuindo, assim, para um processo de exclusão em que esses sujeitos a todo momento são alvos de discursos já cristalizados como incompetentes, preguiçosos, bêbados, animais, entre outros.

$\mathrm{O}$ sujeito indígena, desse contexto, vive impossibilitado de afirmar uma identidade que não seja alvo de preconceito, pois o mesmo não pode ser índio, mas também não pode ser não índio. Isso porque para ser índio precisa de terra e isso não é mais possível, em função da situação de confinamento em que vive, cercado pelos centros urbanos e as fazendas de cana de açúcar e criação de gado e lavoura. Da mesma forma, não pode ser branco, pois os lugares sociais já foram determinados, não há mais espaços para ele.

A situação de minoritarizados vivida pelos indígenas das aldeias de Dourados faz com que esses sujeitos, por mais que busquem ocupar espaços até então negados, não consigam se desvencilhar dos rótulos constituídos historicamente, a ilusão de univocidade parece imperar sobre os mesmos.

Suas identidades não podem ser construídas historicamente, pois antes de qualquer outra identificação eles são índios e ser índio nesse contexto não é positivo 
diante dos olhares da maioria da sociedade não indígena. Nessa direção, Coracini indica que:

\begin{abstract}
Não há identidade possível a não ser na ilusão, na promessa sempre adiada a consciência consigo mesmo, do pertencimento imaginado e inventado a uma nação, a um grupo que iguala ou assemelha aqueles que são desiguais Inassimiláveis. (CORACINI, 2007, p. 49).
\end{abstract}

Essa citação leva-nos a pensar em um imaginário alimentado por diversos discursos como o da ciência e o da história que parecem determinar a identidade do sujeito. Contudo, são esses discursos, vistos como verdades, que impedem a aceitação do outro, do diferente, uma vez que, segundo as discussões das teorias sociais emergentes, essa ilusão de sujeito único, acabado não se sustenta mais.

No que tange às bases colonizadoras é importante destacar as contribuições de Boaventura de Souza Santos, mais especificamente no texto "Entre Próspero e Caliban Colonialismo, Pós-Colonialismo e Interidentidade". Nesse texto o autor se propõe a expor sobre as práticas sociais e discursivas que caracterizam o colonialismo português e o modo como impregnaram os regimes identitários nas sociedades que dele participaram, tanto durante o período colonial, como depois da independência das colônias, com incidência sobretudo, na África e na América.

Ainda sob essa orientação, outra obra do autor, agora com a metáfora "Norte Versus Sul", citada por ele, também entendida como "Linha Abissal", representa, de um lado, o discurso homogêneo e dominante do mundo ocidental, em conflito, com as vozes do Sul, o outro lado da linha, apontadas como vozes de "resistência" ao primeiro, retratando fielmente a situação vivida pelos minorizados e silenciados socialmente, nesse caso aqui, a situação da população indígena.

Nessa direção, de acordo com as orientações dos trabalhos mencionados, direcionados aos silenciamentos do e no dizer, podemos inferir que há uma lógica ocidental em determinar o como e o que deve ser dito, atendendo sempre a um ponto de vista. E isso acontece há 150 anos, decorrente da terminologia do saber, isso pressupõe a existência de uma racionalidade, responsável pela divisão do mundo em Norte e Sul, e, assim, o que se produz discursivamente entre os mesmos, são entendidos como humano e subumano, verdadeiro e falso.

A divisão é tal que "o outro lado da linha" desaparece como realidade, torna-se inexistente e é mesmo produzido como inexistente. Inexistência significa não existir sob qualquer modo de ser relevante ou compreensível. Tudo aquilo que é produzido como inexistente é excluído de forma radical porque permanece exterior ao universo que a própria concepção de inclusão considera como o "outro". A característica fundamental do pensamento abissal é a impossibilidade da co-presença dos dois lados da linha. $\mathrm{O}$ universo "deste lado da linha" só prevalece na medida em que esgota o campo da realidade relevante: para além da linha há apenas inexistência, invisibilidade e ausência não-dialética. (SANTOS, 2010, p.71).

Essa separação é entendida como linha abissal (SANTOS, 2010), onde no lado positivo estão os convencionados como certo, superior, os que estão na legalidade, "normalidade", enquanto que do outro lado, estão os errados, inferiores, os que transitam na ilegalidade, são anormais, logo são instaurados no espaço da inexistência, não reconhecimento, ausência, impossibilitados da co-presença dos dois lados da linha. Essa é a lógica do pensamento ocidental, assim o lado positivo para se afirmar, ser legitimado, precisa silenciar, ocultar, o outro lado, conjuntamente, suas práticas, costumes e seus discursos também são constantemente silenciados. 
A nova conjuntura não permite mais os conceitos de sujeito unificado e defende a substituição de identidade única por fragmentada, o que nos leva a pensar em um sujeito incompleto, em formação constante, ou seja, uma identidade fragmentada. Porém o que era para ser visto como uma posição positiva, pois fragmentado sugere heterogeneidade, diversidade, a partir da conjuntura em que estão os indígenas de Dourados, pode ser entendido como mais um obstáculo na afirmação da identidade.

Considerando que são vistos discursivamente como tutelados, incapazes, muitos estão em situação de mendicância, sem terras suficientes para viverem dos recursos da aldeia e sem religião uma vez que o número de igrejas evangélicas dentro das aldeias é significativo. Ainda destacamos outro fator que pode ser visto como o principal na constituição da identidade; a língua.

A população indígena em questão pode ser considerada um povo sem voz, pois não tem suas línguas representas em nenhum espaço fora do convívio dentro da aldeia. A fragmentação, nesse caso específico, pode ser entendida não como soma, mas como falta.

Falta, não porque é incompleto como todo sujeito constituído na/pela linguagem, mas porque não encontra acolhimento em nenhum dos lados. Esses sujeitos são atravessados a todo tempo por discursos que os impedem, pois são mais de quinhentos anos de efetiva exclusão, logo esse percurso histórico "fala" antes de qualquer outro dizer.

\section{As contribuições da AD e os ecos discursivos em narrativas indígenas}

Em oposição às duas significativas tendências do campo de estudos da linguagem, o estruturalismo e o gerativismo, surge a Análise do Discurso da Escola Francesa (AD) ,na década de 60. No ano de 1969, com a obra, Análise Automática do Discurso, de Michel Pêcheux, a AD arraiga seu marco na história da análise dos discursos e traz a questão do sujeito, até então não considerada com relevância pelos estudos estruturalistas. Um sujeito constituído pela linguagem e interpelado pela ideologia, atravessado pela interação social, considerado como não origem de seu dizer, nesse sentido, a AD, rompe com as concepções estruturalistas.

Considerada como uma disciplina de entremeio, por seu caráter dialógico com a história, a psicanálise e a linguística, a $\mathrm{AD}$ pode ser entendida, também, como transdisciplinar, assim buscando contribuições que fundamentem os discursos e seus efeitos de sentidos a partir das condições de produção. Nessa direção, trabalha com conceitos como o de Formação Ideológica (FI) e Formação Discursiva (FD) enquanto subsídios que fomentam a ocorrência de determinados discursos.

No que tange às características das FIs, cabe destacar que as mesmas constituem um componente dentro dos aspectos da luta de classe nos aparelhos ideológicos althusserianos, “(...)suscetível de intervir como uma força em confronto com outras forças na conjuntura ideológica, característica de uma formação social em dado momento" (PÊCHEUX; FUCHS, 1993, p. 163). Enquanto que as FDs podem ser definidas como:

(...)caso em que se pode definir uma regularidade entre os objetos, os tipos de enunciação, os conceitos, as escolhas temáticas, se puder definir uma regularidade (uma ordem, correlações, posições e funcionamentos, transformações) entre os objetos, os tipos de enunciação, os conceitos, as escolhas temáticas, teremos uma formação discursiva. (FOUCAULT, 2009, p. 43). 
Nessa direção, é possível inferir que não se pode dizer tudo em qualquer lugar, pois em determinados contextos os sentidos podem não ser condizentes. O que vem corroborar no aspecto de que não há um sujeito centralizador do sentido ,de tudo que diz ,pois de acordo Pêcheux (1997), no que intitulou de esquecimentos, há o esquecimento $\mathrm{n}^{\mathrm{o}} 1$, o qual não é acessível ao sujeito, pois é de cunho do inconsciente e do ideológico, o lugar constitutivo da subjetividade e o esquecimento $\mathrm{n}^{\mathrm{o}} 2$, o qual se completa na ilusão de transparência da língua e do sentido, isso é concretizado durante os processos enunciativos, ao realizarmos as escolhas linguística, ao buscarmos o uso de determinadas palavras e não de outras.

Assim, o discurso "Nem tudo que é aplicado na escola da cidade pode ser feito aqui na aldeia, porque as crianças da cidade nascem mais espertinhas que as da aldeia", pode ser enquadrado como sendo da ordem do esquecimento número 2 visto que a professora indígena, ao proferi-lo, tem a ilusão de que esse discurso é seu, não consegue perceber que está repetindo um já dito.

Parece haver uma conscientização por parte dos professores indígenas de todos esses obstáculos ao desenvolvimento da educação escolar indígena, e, também, é visível a percepção de que a avaliação do modelo escolar do não índio não contempla as necessidades da escola indígena. Vale ressaltar aqui as considerações relacionadas à construção da imagem dos índios, valores e avaliações atribuídos aos mesmos que, segundo a autora a seguir, foram inseridos em suas culturas a partir de outro ponto de vista, distinto dos indígenas. Imagem e valores que ao longo tempo são reforçados por discursos como bestialidade, bicho, vadiagem e, principalmente, incompetente, o que inevitavelmente ecoam até o presente momento. São discursos e avaliações nesse sentido que possibilitam narrativas como as que traremos posteriormente. Desse modo, LIMBERTI(2012) sugere que:

Todas as avaliações das relações com os índios, que produziram sua imagem, foram feitas pela escala de valores do não índio e teve um percurso em sua construção. A partir do momento em que o processo de colonização começa a se desenvolver, a imagem do paraíso se desvanece, recategorizando a "bondade" e a "inocência" dos índios. O mesmo discurso que constrói o bom selvagem, constrói, fora do paraíso, o índio como incompetente. (LIMBERTI, 2012, p. 162-163).

Essas questões são recorrentes em nosso cenário, mas por certo são vivenciadas em cenários diversos onde há povos indígenas, moradores de fronteiras, em comunidades de imigração e cenários complexos como são os cenários indígenas. Nesses, principalmente em Dourados, há um olhar negativo quanto à produtividade escolar, que sustenta os discursos como o citado anteriormente. Assim, podemos entender esse discurso como um reflexo da imagem do índio construída durante a história e, juntamente a ele, a avaliação que o professor faz a respeito da competência de seus alunos, pois foi e é dessa forma que são classificados pelos não indígenas e, consequentemente, esse discurso, por ser constante, passa a ser repetido até mesmo pelos próprios indígenas, como num jogo de espelhos, como nos sugere a citação:

Como um caleidoscópio, em que a imagem é o resultado de um arranjo das posições das contas em relação ao jogo de espelhos e ao olho do observador, uma imagem que se cria é o resultado do arranjo entre as impressões(contas) que se tem do objeto, a partir de um imaginário (jogo de espelhos) e do conjunto de expressões e estados da alma (olho) do observador. (LIMBERTI, 2012, p. 139-140). 
Considerando que a imagem é resultado de arranjo e esse está correlacionado ao estado da alma do observador, podemos inferir que a imagem refletida não será provida de avaliação neutra, ou seja, a mesma se constrói a partir de uma ideologia arquitetada sócio historicamente a qual carrega estigmas predeterminados. Logo, se avaliar é considerada uma atividade humana e constante, ela não pode ser vista como uma atividade neutra, sem inferências ideológicas, considerando que toda atividade humana é permeada pelo discurso e que não somos a origem do próprio discurso, avaliar também é resultado de um comprometimento ideológico.

Há um já dito que sustenta o dizer atual, ou seja, há um imaginário social sustentado pelos discursos da existência de um índio que não aprende, que é incapaz, preguiçoso, que permite esse novo dizer de produzir sentido, consequentemente, determinar os lugares sociais a partir das projeções estabelecidas pelas formações imaginárias que indicam os lugares e os discursos entre A e B, dessa forma, o sujeito adéqua seu dizer a partir da imagem que possui do outro e , assim, a interpelação do sujeito se executa a partir da assimilação desse com a formação discursiva que o domina, profere um discurso tendo a ilusão de ser seu, contudo o mesmo está sendo atravessado por outros discursos que já o constituíram.

[.....] esses lugares estão representados nos processos discursivos em que são colocados em jogo. Entretanto, seria ingênuo supor que o lugar como feixe de traços objetivos funciona como tal no interior do processo discursivo; ele se encontra aí representado, isso é, presente, mas transformado; e outros termos, o que funciona nos processos discursivos é uma serie de formações imaginárias que designam o lugar que A e B se atribuem cada um a si e ao outro, a imagem que eles se fazem de seu próprio lugar e do lugar do outro.(PÊCHEUX, 1990, p. 82).

Logo, é possível a inferência de que os indivíduos são interpelados em sujeitos por meio da ideologia e se constituem em relação a outros sujeitos, numa estruturação de inconscientes : há um consciente e um inconsciente que os dividem e, por mais que os mesmos se entendam como origem do sentido, retrocedem aos seus assujeitamentos, pois, ao sair de uma Formação discursiva, já estão totalmente inseridos em outra.

Uma formação discursiva existe historicamente no interior de determinadas relações de classes; pode fornecer elementos que integram em novas formações discursivas, constituindo-se no interior de novas relações ideológicas, que colocam em jogo novas formações ideológicas (PÊCHEUX, 1990, p. 168).

Desse modo, as FDs podem adquirir novos sentidos de acordo com o contexto social em que estiverem inseridas; mesmo sendo pronunciadas em momentos históricos distintos, podem tratar da mesma questão. Porém, o efeito de sentido produzido pelas FDs é condicionado à convenção dos falantes, já que essas estão sujeitas às relações de classes para suas constituições. Assim, os dizeres de hoje são ecos de um já dito anteriormente que se sustentam em novos dizeres, daí a permissão para que ditos, como o da professora indígena, citados acima, não causem espanto para quem ouve, já estão naturalizados.

O discurso só adquire sentido no interior de um universo de outros discursos, lugar no qual ele deve traçar seu caminho. Para interpretar qualquer enunciado, é necessário relacioná-lo a muitos outros - outros enunciados que são comentados, parodiados, citados, etc. (MAINGUENEAU, 2008b, p. 55). 
Os discursos que nutrem o imaginário que constitui a imagem do indivíduo indígena permitem a veiculação de novos discursos da mesma ordem, pois há quinhentos anos ouvimos dizeres nessa direção sobre essa população: o que podemos esperar de um individuo que "trocou suas terras por espelhos"? O discurso do dominador ainda impera, numa relação de efeito de sustentação, destacando que é ela que realiza a articulação entre as proposições constituintes. (PÊCHEUX, 2009, p.101). Portanto, em uma sociedade onde os índios continuam marginalizados esses ditos circulam de forma subliminar.

Dessa forma é inquestionável a força que os discursos dominadores possuem, porque os mesmos são reproduzidos pelos próprios dominados como uma verdade. $\mathrm{O}$ discurso dominante é ao mesmo tempo conformista, seu objetivo maior é manter o status quo, uma certa ordem social, e para isso busca convencer seu dominado de que ele ainda está em vantagem, como podemos observar na narrativa de outro professor indígena. "Então a gente tem a provinha né, que já é um avanço que antes não existia nem isso né(...)", (Professor indígena Guarani, gestor da educação escolar indígena). Isso remete a outros discursos, como por exemplo o da inclusão, mesmo que de forma desigual, pois a provinha não contempla as particularidades da educação escolar indígena. Mais uma vez o indivíduo ao tentar sair de uma FD, pois indica que antes eles "não tinham nem isso", está totalmente inserido em outra, agora na FD do dominador, pois ele se sente incluído.

Ainda no tocante às FDs, o discurso "(...)os pais dos meus alunos falaram que se é pra continuar essa provinha Brasil tinha que ser só em Português, é porque atrapalha ele falou, invés de ajudar tá atrapalhando", (Professor indígena Guarani), nos remete aos discursos da história de extermínio referente às línguas indígenas. Todo processo de educação escolar teve como objetivo a constituição de um país monolíngue, em que somente a língua do dominante fosse aceita. Percebemos, assim, que diante do percurso histórico da sociedade brasileira tentar sustentar a ideia de um país monolíngue é ilusão e que todas as ações que visam normatizar uma língua, estão relacionadas às políticas linguísticas, as quais determinam o lugar e o papel das línguas nas estâncias públicas e juntamente a isso determinam o lugar de seus falantes.

\section{Considerações Finais}

As diferenças étnico-raciais e linguístico-culturais não podem mais serem vistas como espaços esquadrinhados e demarcados, até porque as fronteiras de que falamos pairam acima dos limites duros dos preconceitos e das relações de poder, que vetorizam assimetricamente as forças e circunscrevem posições subalternas e consequentemente preconceituosas. Problematizar os conceitos de "preconceito", de "igualdade", de "tolerância", é mover-se, discursivamente falando, para além dos limiares das "diferenças", dos conceitos estabilizados e circunscritos no âmbito do senso comum.

Sabemos, contudo, que tanto a "realidade", quanto as representações são imagens projetadas, sendo que a proposição de relatar uma dada realidade se dá por percursos instituídos ideologicamente que homologam as representações como verdadeiras. Tais homologações se dão tanto por meio do sujeito enunciador quanto por meio do sujeito enunciatário, pois as relações intersubjetivas os incumbem dos papéis de uma interpretação solidária, dos valores e sentidos partilhados, reservando no interior do senso comum um lugar estável para as verdades socialmente construídas.

As representações são efeitos do imaginário, são atravessadas pelas práticas imaginárias; não existe relação referente-referência há, sim, uma construção discursiva 
do referente, que parece um "já-lá" pelos efeitos de memória. Assim, percebemos que é a partir dessa relação entre memória e esquecimento que são permitidos a elaboração dos sentidos

\section{REFERÊNCIAS}

CURSO DE LICENCIATURA INDÍGENA. Disponível em: http://www.ufgd.edu.br/faed/licenciatura-indigena. Acesso em 05/06/2017.

CORACINI, Maria José. A celebração do outro: arquivo, memória e identidade: línguas (materna e estrangeira), plurilingüismo e tradução. Campinas: Mercado de Letras, 2007.

FIGUEIREDO. A. A. A.: A Provinha Brasil: Os Discursos Inaudíveis de Opressão e Resistência na Educação Escolar Indígena. Dissertação Mestrado. UFGD. MS,2013.

FOUCAULT, Michel. A Arqueologia do Saber. Rio de Janeiro: Forense Universitária, 2009.

LIMBERTI, Rita P.A imagem do índio: discursos e representações. Dourados: Editora

UFGD, 2012.

MACHADO, JOÃO. Bialfabetização e Letramento com Adultos em Guarani/Português: é possível? Um estudo etnográfico do Tetã Guarani - Dissertação de mestrado apresentada ao Programa de Pós - Graduação da Faculdade de Comunicação e Artes - FACALE - UFGD, Dourados - MS. 2013.

MAINGUENEAU, Dominique. Cenas da enunciação. São Paulo: Parábola, 2008.

PEREIRA, MARIA CERES. Naquela comunidade rural, os adultos falam "alemão" e "brasileiros". Na escola, as crianças aprendem o português: um estudo do continnum/escrito em crianças de uma classe bisseriada. Tese de Doutorado Universidade Estadual de Campinas, Instituto de Estudos de Linguagem. Campinas, SP. 1999.

PÊCHEUX, M. Semântica e discurso: uma crítica à afirmação do óbvio. Tradução Eni Orlandi. Campinas, SP: Editora da UNICAMP, 1988.

Pontes, 1997.

O discurso: estrutura ou acontecimento. Trad. EniOrlandi. Campinas, SP:

[1981]. O estranho espelho da análise do discurso. In: COURTINE, JeanJacques. Análise do discurso político - o discurso comunista endereçado aos cristãos. São Carlos: EdufScar, 2009. p. 21-26.

Ideologia, interpelação, "Efeito Münchhausen". In: Semântica e discurso: uma crítica à afirmação do óbvio. Campinas, SP, Editora da Unicamp, 2009, p.137-144.

Análise Automática do Discurso. Trad. Eni P. Orlandi. In: GADET, Françoise. HAK, Tony. (Org.). Por uma Análise Automática do Discurso. Uma Introdução à Obra de Michel Pêcheux. Campinas, SP: Editora da UNICAMP, p. 61-161, (1990 a [1969]).

SANTOS, B. S. Para além do Pensamento Abissal: Das linhas globais a uma ecologia de saberes. In: Critical Review of Social Sciences, 78, October 2010,p. 3-46. 
. Entre próspero e caliban: colonialismo, pós-colonialismo e interidentidade. A gramática do tempo: para uma nova cultura política. São Paulo: Cortez, 2006. Capítulo 7, p. 227 - 276. (Coleção para um novo senso comum; v. 4).

SGARBI, N. M. F. Q. Interdiscursos sobre educação escolar indígena: opressão e resistência. Relatório de Pós-Doutoramento. UEMS. MS. 2016.

Recebido em: junho de 2017.

Aprovado em: julho de 2017.

\section{Como citar este trabalho:}

SGARBI, N. M. F. de Q.; FIGUEIREDO, A. A. de A. Educação escolar indígena e os reflexos de um imaginário social: uma leitura sob o viés da análise do discurso. Traços de linguagem, v. 1, n. 1, p. 9-19, 2017. 